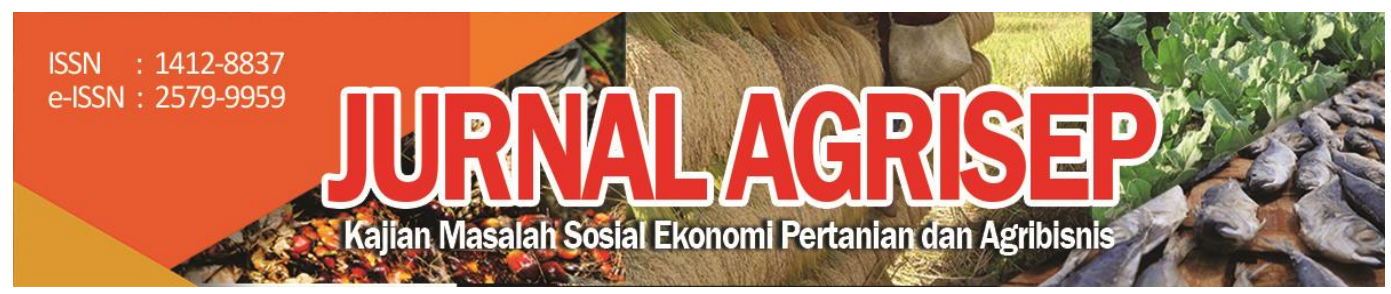

DOI: 10.31186/jagrisep.20.1.129-140

\title{
PENGARUH E-COMMERCE TERHADAP FLUKTUASI HARGA DAN PENINGKATAN PENDAPATAN PETANI CABAI RAWIT
}

\section{E-commerce Utilization of Price Fluctuation and Increasing Income of Raw Chili Farmers}

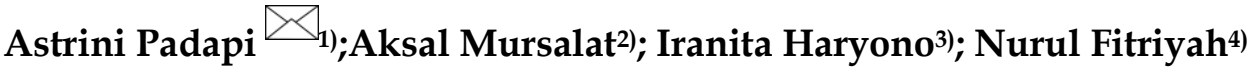 \\ 1,2,3,4)Program Studi Agribisnis Fakultas Sains dan Teknologi Universitas \\ Muhammadiyah Sidenreng Rappang \\ Email: astrinipadapi@umsrappang.ac.id
}

\begin{abstract}
This paper is aimed to examine how the influence of e-commerce use on the income of cayenne pepper farmers, but it is related to the price fluctuation of cayenne pepper. The price fluctuation of raw chilli here acts as an intermediate variable so that this research will be analyzed using Path Analysis. This research uses a quantitative design with a case study research technique. This research was conducted in Ongkoe Village, to be precise in the Machero neighborhood, Belawa District, Wajo Regency, South Sulawesi. The results of path analysis illustrate that indirectly the use of e-commerce through fluctuations in chili prices has a significant effect on increasing farmers' income. Even though it is of small value, it is hoped that farmers can find and take advantage of existing e-commerce in carrying out their daily activities. It is hoped that farmers can find and utilize e-commerce in order to bypass long marketing channels so that consumers do not get higher prices and farmers can sell their crops at a satisfactory price.
\end{abstract}

Keyword: E-commerce, Increasing Income, Raw Chili.

\section{ABSTRAK}

Penelitian ini bertujuan untuk memaparkan bagaimana pengaruh pemanfaatan Ecommerce terhadap pendapatan petani cabe rawit, namun dihubungkan dengan fluktuasi harga cabai rawit. Fluktuasi Harga cabai rawit disini berperan sebagai variabel antara sehingga penelitian ini akan dianalisis menggunakan Analisis Path. Penelitian menggunakan desain kuantitatif dengan teknik penelitian studi kasus. Penelitian ini dilaksanakan di Desa Ongkoe, tepatnya di lingkungan Machero, Kecamatan Belawa 
Kabupaten Wajo Sulawesi Selatan. Hasil analisis jalur menggambarkan bahwa secara tidak langsung Pengaruh E-commerce melalui Fluktuasi harga cabai mempunyai pengaruh signifikan terhadap Peningkatan pendapatan petani. Walaupun bernilai kecil diharapkan petani dapat menemukan dan memanfaatkan E-commerce yang ada dalam melaksanakan kegiatan mereka sehari-hari. Diharapkan agar petani dapat menemukan dan memanfaatkan E-commerce demi memotong jalur pemasaran yang panjang sehingga konsumen tidak mendapatkan harga yang lebih mahal dan petani dapat menjual hasil taninya dengan harga yang memuaskan.

Kata Kunci: E-commerce, Peningkatan Pendapatan, Cabai Rawit.

\section{PENDAHULUAN}

Salah satu penggemar cabai tersebar dunia merupakan warga indonesia. Oleh karena itu cabai merupakan satu diantara produk primadona pangan Indonesia. Bagi data Kementrian pertanian, luas panen cabe rawit di Sulawesi Selatan spesialnya hadapi perkembangan sebesar 24, 41 dari tahun tadinya tahun 2017. Salah satu kasus yang terjadi di kecamatan Belawa adalah petani cuma bisa panen beberapa kali dalam setahun, diakibatkan banjir tahunan kiriman dari Danau Tempe. Bila jumlah cabai menurun dari permintaan hingga terjadinya peningkatan harga. Begitu pula sebaliknya, bila pasokan cabai berlebih kebutuhan hingga harga jual kembali turun. Bila musim hujan atau waktu perayaan hari besar biasanya harga cabai bertambah tinggi sehingga mempengaruhi tingkatan inflasi. Salah satu langkah yang sangat efektif dalam pemasaran pada era mileal ini merupakan pemanfaatan $e$ - commerce.

Rantai distribusi penjualan hasil pertanian lebih dipersingkat. Menurut (Sengkey \& Tulung, 2017) Petani yang telah mendapatkan sosialisasi telah mampu/ dapat menggunakan teknologi informasi dalam hal ini internet untuk mencari informasi-informasi yang mereka butuhkan dalam mengelola hasil pertanian mereka dan juga mempunyai pengetahuan dalam menerapkan $E$ commerce dalam menjual hasil-hasil pertanian sehingga dapat meningkatkan daya saing petani. Perihal ini bisa dikategorikan sebagai salah satu langkah dalam mengefisiensikan rantai nilai hasil pertanian, supaya bisa mengenali pengaruh pemanfaatan $e$ - commerce terhadap pemasukan petani cabe rawit dan fluktuasi harga cabai. Dalam hal ini dibatasi dalam lingkungan Desa Ongkoe, Kecamatan Belawa, Kabupaten Wajo Sulawesi Selatan. Hal inilah yang melatarbelakangi penelitian dengan judul "Pengaruh E-commerce terhadap Fluktuasi Harga dan Pendapatan Petani Cabe Rawit (Studi kasus Desa Ongkoe, Kecamatan Belawa, Kabupaten Wajo, Sulawesi Selatan). 


\section{METODE PENELITIAN}

\section{Rancangan Penelitian}

Tema penelitian ini "Pengaruh E-commerce terhadap Fluktuasi Harga dan Pendapatan Petani Cabe Rawit" adalah penelitian yang memaparkan bagaimana pengaruh E-commerce terhadap pendapatan petani cabe rawit, namun dihubungkan dengan fluktuasi harga cabai rawit.

\section{Populasi dan Sampel}

Penelitian ini termasuk dalam explanatory research yang menjelaskan dengan pendekatan kuantitatif. Penelitian eksplanatori adalah penelitian yang ditujukan untuk menjelaskan bagaimana atau mengapa suatu phenomena terjadi atau beroperasi (Dane (1990); dan Sukiyono (2018)). Populasi riset ini berjumlah sekitar 230 petani cabai rawit yang akan dilakukan pengambilan sampel sebanyak 100 petani. Dalam hal ini dibatasi dalam lingkungan Desa Ongkoe, Kecamatan Belawa, Kabupaten Wajo Sulawesi Selatan. Penelitian ini dilaksanakan di Desa Ongkoe, tepatnya di lingkunagan Machero, Kecamatan Belawa Kabupaten Wajo Sul-Sel. Lokasi dipilih secara sengaja (purposive) Daerah Lingkungan Machero ini adalah daerah pengahasil cabe rawit. Penelitian ini akan dilaksanakan bulan Agustus sampai bulan Oktober 2020.

\section{Teknik Analisis Data}

Fluktuasi Harga cabai rawit disini berperan sebagai variabel antara sehingga penelitian ini akan dianalisis menggunakan Analisis Path. Garson, (2013); dan Streiner, (2005) menjelaskan bahwa dalam analisis jalur efek langsung terjadi secara langsung dari satu variabel ke variabel lainnya, dan efek tidak langsung adalah efek yang dimediasi oleh variabel lain. Objek yang diteliti yaitu analisis Path yang mencari pengaruh pemanfaatan E-commerce, fluktuasi harga cabai terhadap pendapatan petani cabai rawit. Berikut hipotesis penelitian:

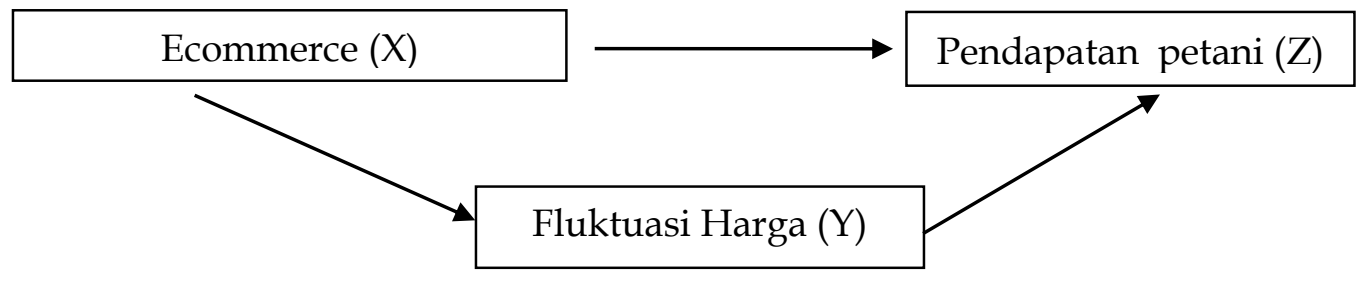

Gambar 1.

Model Hipotesis 
H1: Terdapat pengaruh secara langsung antara E-commerce $(X)$ terhadap Fluktuasi Harga (Y)

H2: Terdapat pengaruh secara langsung antara Pengaruh E-commerce $(X)$ dan Fluktuasi Harga ( $Y$ ) terhadap Pendapatan Petani (Z)

H3: Terdapat pengaruh secara langsung antara Pengaruh E-commerce $(X)$ melalui Fluktuasi Harga (Y) terhadap Pendapatan Petani (Z).

Analisis Path menggunakan bantuan aplikasi SPSS, dimana hasil kesimpulannya hendak akan ditafsirkan informasi hasil pengolahan dengan mencermati (a) Standardized coefficient ataupun Beta yang akan menjadi koefisien jalur( P); (b) Uji model pada taraf signifikan $a=5 \%$ (Nilai Fhitung); dan (c) Sigfikasi koefisien jalur (Nilai thitung buat tiap- tiap Beta) yang akan menjadi nilai koefisien jalur.

Tahapan dalam analisis jalur ini terdiri dari (a) Asumsi- asumsi klasik regresi linear berganda di uji saat sebelum melanjutkan ke analisis jalur, (b) Tahapan penentuan persamaan structural, (c) Sesi menghitung kontribusi variable $X, Y$, serta $Z$ buat menampilkan nilai sumbangan, (d) Sesi memastikan koefisien e sehingga tercipta kesesuaian model, (e) Sesi akhir penentuan pengaruh langsung, tidak langsung serta pengaruh total, (f) Sesi interpretasi hasil serta penarikan kesimpulan.

\section{HASIL DAN PEMBAHASAN}

\section{Kondisi Lokasi Penelitian}

Sebagai salah satu primadona pangan di Indonesia, menurut data Kementrian pertanian, luas panen cabe rawit di Sulawesi Selatan khususnya mengalami pertumbuhan sebesar 24,41 dari tahun sebelumnya tahun 2017. Salah satu permasalahan yang terjadi di kecamatan Belawa adalah petani hanya dapat menanam sekali dalam setahun, disebabkan banjir tahunan kiriman dari Danau Tempe.

Kelurahan Machero memiliki luas wilayah 9,94 $\mathrm{Km}^{2}$ secara administrasi terdapat 2.560 jiwa. Beberapa masyarakat yang berada di desa Marchero masih banyak yang memiliki pendapat dibawah rata-rata. Sumber pendapatan masyarakat di desa Mario diantaranya adalah pengarap sawah dan kebun. Kelurahan Machero mempunyai sejarah serta nilai sosial budaya dan solidaritas sosial yang telah terbangun semenjak masih terletak pada komunitas petani. Saat ini memang sudah banyak program-program yang dikembangkan untuk membantu pengembangan masyarakat petani namun masih bersifat parsial. Dari berbagi program yang di berikan kepada masyarakat masih perlu di lakukan pembinaan teknis. Jarak lokasi Mitra di Kelurahan Machero Kecamatan Belawa Kabupaten Belawa ke kota Rappang Kabupaten Sidrap adalah 31,9 km. 
Kelurahan machero memiliki potensi yang masih cukup bagus dibeberapa potensi yang berada di keluarahan machero diantaranya budidaya cabai rawit. Sehingga peneliti memilih lokasi ini menjadi lokasi Penelitian ini. Penelitian ini bermula dari pendanaan PDP Ristekdikti tahun 2020. Penelitian ini bertujuan mengetahui bagaimana tingkat pemanfaatan E-commerce petani cabai. Sehingga peneliti hibah PDP dapat mencari solusi kedepannya bila terdapat permasalahan selama pengambilan data kuisioner.

\section{Pemanfaatan E-commerce}

E-commerce merupakan proses jual beli produk yang dilakukan via elektronik oleh konsumen serta dari industri dengan komputer (perantara transaksi bisnis) (Apriadi \& Saputra, 2017). E-commerce sebaiknya dipraktekkan industry yang akan berkembang pesat pertumbuhan pengguna internet. Walaupun perkembangan E-commerce tidak sebanding dengan perkembangan internet. Fenomena e- commerce belum bisa dimengerti serta didukung dengan baik sangat utama di negeri tumbuh semacam indonesia. Keyakinan terhadapa keamaan dan produk realitanya belum dimiliki konsumen yang memanglah belum mempunyai keahlian buat itu (Pranata \& Darma, 2014).

Guna tingkatkan manfaat dari konsumsi E-commerce itu sendiri, dibutuhkan uraian dari penyedia layanan E-commerce buat menenkankan keuntungan( kenyamanan, guna dan yang lainnya) dalam pelayanannya. Komsumen sebaiknya terbiasa terlebih dulu serta menikmati dalam menggunakan teknologi sehabis itu mereka bisa merasakan khasiat dari teknologi yang digunakan (Monica \& Tama, 2017).

Kualitas web yang merupakan aspek pendukung dalam industri sepatutnya memperlihatkan kehadiran industry agar konsumen virtual percaya dan bersedia transaksi secara online lewat industri tersebut (Sarwono \& Prihartono, 2012).

\section{Hasil dan Pembahasan Analisis Jalur}

Berikut merupakan hasil analisis jalur berdasarkan wawancara 100 petani tersebut: 


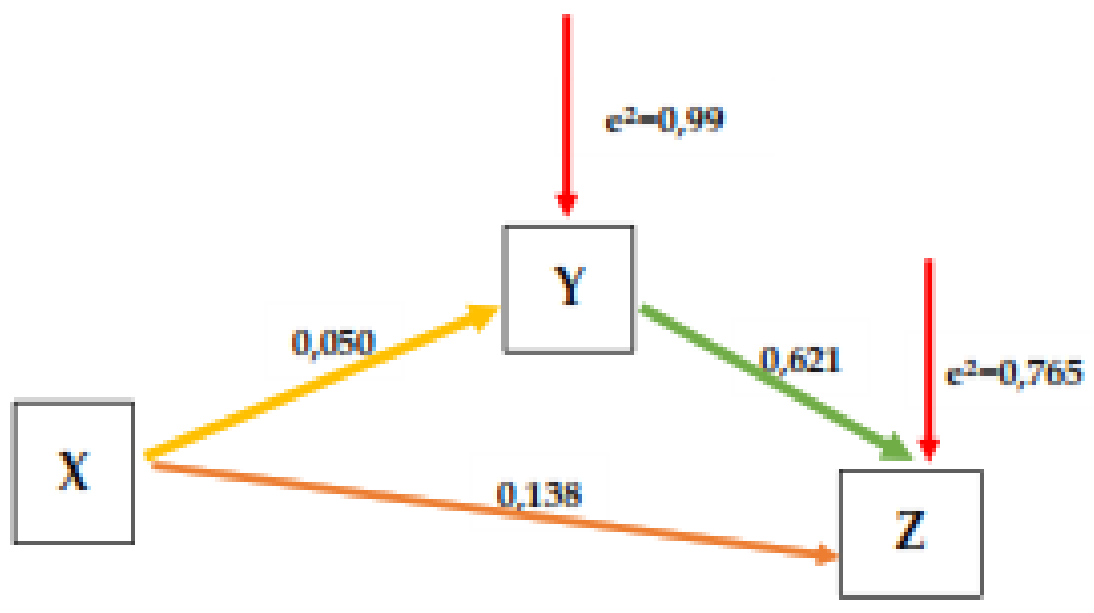

Gambar 2.

Hasil Analisis Jalur

Hasil Pengujian Hipotesis:

1. Struktur pertama

Sebagaimana nampak pada Gambar 2 bahwa struktur pertama model hubungan kausal duji adalah pngaruh E-commerce $(\mathrm{X})$ terhadap Fluktuasi Harga Cabai Rawit (Y) disajikan dalam tabel 1.

Hasil output Regresi Model I dari kedua variable yaitu $x=0,619$ lebih besar dari 0,05 (nilai signifikasi). Sehingga Regresi Model I yakni variabel Ecommerce $(\mathrm{X})$ tidak berpengaruh signifikan terhadap Fluktuasi Harga $(\mathrm{Y})$. Pengaruh $\mathrm{X}$ terhadap $\mathrm{Y}$ adalah sebesar $0,3 \%$ yang menjadi Besaran nilai $\mathrm{R}^{2}$, sisanya $90,7 \%$ ialah dari variable-variabel lain yang tidak dirumuskan riset ini. $\mathrm{U}$ nilai $\mathrm{e} 1=0,99$ berasal dari rumus e $1=\sqrt{ }(1-0,003)$

Tabel 1. Pengaruh Variable E-commerce $(\mathrm{X})$ terhadap Fluktuasi Harga Cabai Rawit (Y)

\begin{tabular}{|c|c|c|c|c|}
\hline Model & B & Beta & $T$ & Sig, \\
\hline$X$ & 22,355 & 0,050 & 0,500 & 0,619 \\
\hline $\mathbf{R}$ & \multicolumn{4}{|c|}{0,500} \\
\hline $\mathbf{r}_{2}$ & \multicolumn{4}{|c|}{0,003} \\
\hline
\end{tabular}

Sumber: Data Primer diolah 
2. Struktur Kedua

Seperti tersaji pada gambar 2 bahwa struktur kedua model hubungan kausal duji adalah pengaruh E-commerce $(X)$ dan Fluktuasi Harga Cabai Rawit (Y) terhadap Pendapatan Petani (Z) pada tabel 1.

\section{Tabel 2. Pengaruh Fluktuasi Harga Cabai Rawit (Y) terhadap Pendapatan Petani (Z)}

\begin{tabular}{|c|c|c|c|c|}
\hline Model & B & Beta & $T$ & Sig, \\
\hline$X$ & 7,581 & 0,138 & 1,779 & 0,78 \\
\hline Y & 1,024 & 0,621 & 7,993 & 0,000 \\
\hline $\mathbf{R}$ & \multicolumn{4}{|c|}{0,643} \\
\hline $\mathbf{r}_{2}$ & \multicolumn{4}{|c|}{0,414} \\
\hline
\end{tabular}

Sumber: Data Primer diolah

Hasil output Model II dari ketiga variable yaitu $X=0,078$ (nilai signifikansi) $>0,05$ dan $Y=0,000<0,05$. Sehingga dalam Regresi Model II, varibel y secara signifikan berpengaruh kepada $\mathrm{z}$ dan variable $\mathrm{x}$ tidak. Angka 0,414 (Nilai model summary) berarti nilai pengaruh $X$ dan $Y$ terhadap Z adalah sebesar $41,4 \%$ (besaran nilai $\mathrm{R}^{2}$ ). Sisanya dari variable lain yang tidak tercantum dalam riset. Nilai e2 0,765 meruapakan hasil $=\sqrt{ }(1-0,414)$.

Berdasarkan 2 (dua) struktur yang telah dijelaskan sebelumnya, maka hasil dari tahap uji Hipotesis dan Pembuatan kesimpulan dapat dijelaskan sebagai berikut:

a. Hasil Analisa pengaruh variable $\mathbf{X}$ terhadap $\mathbf{Y}$, nilai signifikasinya adalah 0,619 , yang nilainya $>0,05$. Sehingga secara langsung E-commerce tidak terlihat pengaruh yang signifikan terhadap Fluktuasi harga cabai rawit.

Hasil tahap uji Hipotesis pertama adalah secara langsung Ecommerce tidak berpengaruh signifikan terhadap Fluktuasi harga cabai rawit. Hal ini sejalan dengan penelitian (Nurlaela, 2018) bahwa besarnya kontribusi media E-commerce terhadap peningkatan pendapatan adalah kurang dari $50 \%$ sisanya dipengaruhi oleh factor lain. Harapan masyarakat adalah harga pangan yang sewajarnya. Fluktuasi harga cabai sering sekali terjadi. Terdapat gejala di Indonesia terjalin perbandingan harga cabai antar daerah dalam sesuatu periode tertentu (Nauly, 2017). Menurut (Riyadh, 2019) satu upaya dalam peningkatan efisiensi pemasaran yakni mepersiapkan klembagaan petani yang kuat guna terampil berwirausaha dalam mmbina petani. Sehingga dapat memaksimalkan pemanfaatkan $E$ commerce bagi para petani. 
b. Hasil Analisa pengaruh variable $\mathbf{x}$ terhadap $\mathrm{z}$, Besarnya adalah $0,078>$ 0,05. Sehingga E-commerce secara langsung tidak berpengaruh signifikan terhadap Peningkatan pendapatan petani.

Hasil tahap uji Hipotesis kedua adalah secara langsung E-commerce tidak terlihat pengaruh signifikan terhadap Peningkatan pendapatan petani. Permasalahan mengapa pemanfataan ecoomerce tidak berpengauh signifikan terhadap pendapatan petani adalah kesulitan pemasaran produk pertanian serta keterbatasan sumber daya manusia. Hal tersebut bertolak belakang dengan beberapa penelitian terdahulu. Dalam (Cahyono et al., 2020) semakin tinggi adopsi teknologi informasi sister E-commerce dalam UMKM, maka semakin tinggi pula kinerja. Riset lain dilakukan (Maryama, 2013) mengemukaan kalau manfaat terbanyak dari pemanfaatan E-commerce merupakan meningkatnya omzet penjualan sebesar 31\%. Dalam (Pradipta et al., 2015) melaporkan bahwa perusahaan yang memakai E-commerce hendak mendapatkan keuntungan ialah(1) munculnya sumber pendapatan baru yang lebih terlihat hasilnya bila dibandingkan dari sistem transaksi tradisional,(2) tingkatkan pasar yang exprosure,(3) merendahkan biaya operasional,(4) melebarkan jangkauan,(5) tingkatkan kesetiaan pelanggan,( 6) meningkatan manajemen pemasok,(7) memperpendek waktu produksi serta( 8) tingkatkan rantai nilai.

c. Hasil Analisa pengaruh variable y terhadap z, nilai $0,00<0,05$. Sehingga dapat diperoleh kesimpulan bahwa secara langsung fluktuasi harga cabai terlihat memiliki pengaruh yang cukup signifikan terhadap peningkatan pendapatan petani.

Hasil tahap uji Hipotesis ketiga adalah secara langsung fluktuasi harga cabai berpengaruh signifikan terhadap peningkatan pendapatan petani. Keresahan warga konsumen cabai adalah terjadinya fluktuasi harga musiman yang nyaris tiap tahun. Peningkatan harga cabai disebabkan kurang pasokan sbaliknya prmintaan tetap dan continue terlebih meningkat pada masa tertentu. Dalam (Farid \& Subekti, 2012) Naik turunnya harga cabai terjadi dikarenakan masalah musim, hujan, permasalahan produksi, serta saluran distribusinya. Dalam (Apriadi \& Saputra, 2017). Konsumen akan mendapatkan harga murah bila petani dapat menjual langsung dan keuntungan yang diperoleh oleh petani akan meningkat.

\section{d. Hasil Analisa pengaruh $x$ melalui $Y$ terhadap $Z$}

Pengaruh langsung yang $X$ terhadap $z=0,138$. Pengaruh tidak langsung $Y$ terhadap $Z=(\text { nilai Beta } X \text { ke } Y)^{*}($ Nilai Beta $Y$ ke $z)=0,050 \times 0,621=0,032$. Sehingga pengaruh langsung total yang diberikan $\mathrm{x}$ terhadap $\mathrm{z}=$ pengaruh langsung + pengaruh tidak langsung $=0,138+0,032=0,17$. Jadi nilai pengaruh tidak langsung $>$ pengaruh langsung. Secara tidak langsung $E-$ 
commerce melalui Fluktuasi harga cabai memiliki pengaruh signifikan terhadap Peningkatan pendapatan petani. Hal inilah yang ditampilkan dalam Gambar 2.

Hasil tahap uji Hipotesis keempat adalah melalui fluktuasi harga cabai, E-commerce memberi pengaruh terhadap peningkatan pendapatan petani cabai. Walaupun secara parsial, nilai pengaruh yang diberikan sangat kecil. Terdapat beberapa factor lain yang memiliki pengaruh besar dalam pemanfaatan E-commerce, namun tidak masuk dalam penelitian ini yakni karakteristik individu (umur dan kesediaan alat TIK) serta kebutuhan informasi mngenai tekhnologi pngolahan hasil, pemasaran serta iklim. Menurut (Elian et al., 2014) pnggunaan internet masih tergolong rendah disebabkan dalam pertimbangan kebutuhan, hubungan penggunaan internet dengan informasi pemasaran, serta pertimbangan petani daam mengembangkan usaha taninya. Informasi yang mereka dapatkan didiskusikan bersama penyuluh, disebar da nada yang disimpan pribadi.

Saat ini terdapat sikap konsumen yang cenderung lebih menggemari belanja dari dalam rumah serta menuntut produsen, tercantum kelompok tani serta koperasi tani buat menyesuaikan diri dari pemasaran secara offline ke $e$ commerce. Aku memandang sistem e-commerce dibutuhkan buat kurangi tingkatan kontak langsung antar manusia. Sistem e- commerce pula lebih cepat serta praktis dalam penggunaannya. Contoh e-commerce yang dapat dimanfaatkan petani dan konsumen adalah Agribisnis Store, aplikasi yang khusus memasarkan produk pertanian, perikanan dan peternakan. Aplikasi ini dikembangkan oleh Program studi Agribisnis, Universitas Muhammadiyah Sidenreng Rappang. Semoga kedepannya ada banyak petani yang dapat memanfaatkan aplikasi ini dan memperluas jaringan pasar mereka dan menekan harga jual dalam mengifisienkan rantai pemasaran cabai rawit dan produk pertanian lainnya (Padapi et al., 2020).

Perihal ini karena promosi via online diharapkan lebih mudah dalam menjangkau konsumen perihal memperkenalkan/menjual produknya. Ecommerce memudahkan antara konsumen serta produsen dalam melaksanakan transaksi (Helmalia \& Afrinawati, 2018). Dalam riset yang dicoba (Xing, 2018) pula melaporkan kalau pemakaian $e$ - commerce signifikan berakibat pada kenaikan kegiatan perdagangan. Lewat $e$-commerce baik orang maupun industri bisa mencari sumber benda serta jasa( produsen) serta menjual produk yang dipunyai dengan lebih efektif tanpa terdapat hambatan waktu serta jarak. Menurut (Vincent et al., 2014) aplikasi E-commerce membantu pemilik dalam membuat untuk mengontrol penjualan yang dilakukan.

Hasil Riset terdahulu oleh Spiicaalmilia dan Robahi( 2007) dalam (Rahmidani, 2015) menampilkan kalau manfaat terbesar pemakaian E-commerce pada industri merupakan bisa meningkatkan omzet penjualan, kenaikan jumlah 
pelanggan, ekspansi jangkauan bisnis dan hubungan kedekatan. Menurut (Nasution, 2008) Informasi menjadi isu penting dalam keberterimaan pengguna atas teknologi. Menurut (Irmawati, 2011) dengan memakai E-commerce, penjual/produsen dapat merubah catatan harga ataupun mlaksanakan kustomasi prduk ataupun jasa yang ditawarkan serta trinformasikan secara cepat melalui website. Suatu umumnya membutuhkan waktu yang lama yang dilaksnakan ataupun diintergrasikan, dengan e- commerce jadi lebih cepat. Menurut Hayono dkk (2020) program pemberdayaan masyarakat menjadi kurang efektif karena bersifat top-down (tidak mmperhatikan aspirasi, kbutuhan serta kmampuan masyarakat yang brsangkutan).

\section{SIMPULAN DAN SARAN}

\section{Simpulan}

Hasil analisis jalur menggambarkan bahwa secara tidak langsung $E$ commerce memiliki pengaruh melalui Fluktuasi harga cabai mempunyai pngaruh signifikan terhadap Peningkatan pendapatan petani. Pihak Individu maupun perusahaan (melalui E-commerce) dapat mncari sumber barang \& jasa (produsen) dan mnjual produk akan lebih efisien tanpa ada kendala masa pengiriman serta jarak tempuh. Walaupun bernilai kecil diharapkan petani dapat menemukan dan memanfaatkan E-commerce yang ada dalam melaksanakan kegiatan mereka sehari-hari.

\section{Saran}

Diharapkan agar petani dapat menemukan dan memanfaatkan E-commerce demi memotong jalur pemasaran yang panjang sehingga konsumen tidak mendapatkan harga yang lebih mahal dan petani dapat menjual hasil taninya dengan harga yang memuaskan.

\section{DAFTAR PUSTAKA}

Apriadi, D., \& Saputra, A. Y. 2017. E-Commerce Berbasis Marketplace Dalam Upaya Mempersingkat Distribusi Penjualan Hasil Pertanian. Jurnal RESTI (Rekayasa Sistem Dan Teknologi Informasi). 1(2): 131-136.

Cahyono, B., Setyowati, R., \& Ihsaniyati, H. 2020. Adoption of Cyber Extension by Agricultural Extension Workers (PPL) and Factors Affecting. Jurnal Penyuluhan. 16(2): 240-249.

Dane, Francis C. 1990. Research Methods. Bookd/Cole Publishing Company. California

Elian, N., Lubis, D. P., \& Rangkuti, P. A. 2014. Penggunaan Internet Dan Pemanfaatan Informasi Pertanian Oleh Penyuluh Pertanian di 
Kabupaten Bogor Wilayah Barat. Jurnal Komunikasi Pembangunan. 12(2): 104-109.

Farid, M., \& Subekti, N. A. 2012. Tinjauan Terhadap Produksi, Konsumsi, Distribusi Dan Dinamika Harga Cabe Di Indonesia. Buletin Ilmiah Litbang Perdagangan. 6(2): 211-234.

Garson, G.D., 2013. Path Analysis. Statistical Associates Publishing.

Helmalia, H., \& Afrinawati, A. 2018. Pengaruh E-Commerce Terhadap Peningkatan Pendapatan Usaha Mikro Kecil Dan Menengah di Kota Padang. JEBI (Jurnal Ekonomi Dan Bisnis Islam). 3(2): 237-246.

Irmawati, D. 2011. Pemanfaatan E-Commerce Dalam Dunia Bisnis. Jurnal Ilmiah Orasi Bisnis-ISSN, 2085, 1375.

Maryama, S. 2013. Penerapan E-Commerce Dalam Meningkatkan Daya Saing Usaha. Liquidity. 2(1): 73-79.

Monica, N., \& Tama, A. I. 2017. Pengaruh Persepsi Manfaat, Persepsi Kemudahan, Persepsi Kenyamanan, Norma Subjektif dan Kepercayaan Terhadap Minat Menggunakan Electronic Commerce. JRAK: Jurnal Riset Akuntansi Dan Komputerisasi Akuntansi. 8(1): 29-44.

Nasution, D. 2008. Senjangan Gender terhadap Motivasi dan Self-Efficacy pada Keberterimaan Teknologi Informasi. Jurnal Organisasi Dan Manajemen. 4(1): 10-19.

Nauly, D. 2017. Fluktuasi Dan Disparitas Harga Cabai di Indonesia. Jurnal Agrosains Dan Teknologi. 1(1): 57-70.

Nurlaela, N. 2018. Efektifitas Penggunaan Media E-Commerce Terhadap Peningkatan Pendapatan UMKM Depok Dilihat Dari Etika Bisnis. Seminar Nasional Dan Diskusi Panel Multidisiplin Hasil Penelitian Dan Pengabdian Kepada Masyarakat 2018. 1(1): 152- 156

Padapi, A., R, F., Mursalat, A., \& Haryono, I. 2020. PENGANTAR ECOMMERCE.

Pradipta, A. A., Prasetyo, Y. A., \& Ambarsari, N. (2015). Pengembangan Web ECommerce Bojana Sari Menggunakan Metode Prototype. EProceedings of Engineering, 2(1): 1042-1056

Pranata, I. M. A., \& Darma, G. S. 2014. Strategi Penerapan E-Commerce Dalam Meningkatkan Keunggulan Bersaing. Jurnal Manajemen Bisnis. 11(1): 6981.

Rahmidani, R. (2015). Penggunaan E-Commerce Dalam Bisnis Sebagai Sumber Keunggulan Bersaing Perusahaan. Prosiding Seminar Nasional Ekonomi Manajemen Dan Akutansi (SNEMA), 345-352.

Riyadh, M. I. 2019. Analisis Saluran Pemasaran Lima Pangan Pokok dan Penting di Lima Kabupaten Sumatera Utara [Analysis of Marketing Channel of 
the Five Essentials and Important Food in Five Districts of North Sumatra]. Jurnal Ekonomi \& Kebijakan Publik. 9(2): 161-171.

Sarwono, J., \& Prihartono, K. 2012. Perdagangan Online: Cara Bisnis di Internet. Jakarta: PT Elex Media Komputindo.

Sengkey, R., \& Tulung, N. M. 2017. IbM Pemanfaatan E-Commerce Dalam Memasarkan Hasil-Hasil Pertanian. Jurnal Teknik Elektro Dan Komputer. 6(3): 111-116.

Streiner, D.L., 2005. Finding our way: an introduction to path analysis. Can. J. Psychiatr. 50(2), 115-122

Sukiyono, K. 2018. Penelitian Survai Dan Teknik Sampling. BPFP. Universitas BEngkulu

Vincent, T. B., Rostianingsih, S., \& Tjahyana, L. J. 2014. Aplikasi E-commerce Untuk Percetakan Online PT. Visa Bintang Semesta. Jurnal Infra. 2(2): 139-142.

Xing, Z. 2018. The impacts of Information and Communications Technology (ICT) and E-commerce On Bilateral Trade Flows. International Economics and Economic Policy. 15(3): 565-586. 